\title{
Investigating the Effect of Climatic Factors of Roshtkhar Town (Khorasan Razavi, Iran) on the Development and Cultivation of Pistachio Using GIS Software
}

\author{
Hassan Rahmanpour1 ${ }^{*}$, Esmail Arjomand2, Fatemeh Akrami², Mahdi K. Hoshtinat ${ }^{3}$ \\ ${ }^{1}$ Young Researchers and Elite Club, Torbat-e Heydarieh Branch, Islamic Azad University, Torbat-e Heydarieh, Iran \\ ${ }^{2}$ Geography \& Secretary Education, Roshtkhar City, Iran \\ ${ }^{3}$ Sociology \& Secretary Education, Roshtkhar City, Iran \\ Email: *rhmanpor@yahoo.com
}

Received 14 April 2016; accepted 27 August 2016; published 30 August 2016

Copyright (C) 2016 by authors and Scientific Research Publishing Inc.

This work is licensed under the Creative Commons Attribution International License (CC BY). http://creativecommons.org/licenses/by/4.0/

(c) (i) Open Access

\section{Abstract}

The use of Geographic Information System (GIS) has significantly helped managers provide optimal models of sustainable agricultural development, identify local features related to agricultural production and their proper zoning, identify agricultural needs and constraints and finally provide the appropriate structure of land use. The main purpose of this study was to determine areas capable of cultivating Pistachio according to the parameters affecting the Pistachio cultivation in Roshtkhar town. Statistics of meteorological stations of the town were taken from Meteorology Organization of Khorasan Razavi for the period of 1989-2010 in order to determine climatic parameters required to cultivate Pistachio. For mapping surface elevation, slope, aspect, and TIN of the geographic organization of armed forces with a scale of 1:250,000 topographic maps were used. For mapping vegetation and land use in the area under study, land capability map of the area on a scale of 1:250,000 from the institute of soil and water was used. Also information on cultivation and annual production of agricultural statistics, published by Agriculture was used. Finally, it was concluded that the northeast and southwest of Roshtkhar town are the most prone areas to cultivate Pistachio.

\section{Keywords}

Pistachio, Roshtkhar City, Prone Areas, Environmental Factors (Climate and Natural), Geographical Information Systems

\footnotetext{
${ }^{*}$ Corresponding author.
}

How to cite this paper: Rahmanpour, H., Arjomand, E., Akrami, F. and Hoshtinat, M.K. (2016) Investigating the Effect of Climatic Factors of Roshtkhar Town (Khorasan Razavi, Iran) on the Development and Cultivation of Pistachio Using GIS Software. Open Journal of Geology, 6, 963-970. http://dx.doi.org/10.4236/ojg.2016.68072 


\section{Introduction}

Latin word Pistachio is derived from its name in the Persian language, Peste or Piste. Khanlari believed that the Persian word Peste is originated from the people of Northern areas of Khorasan, which is a very ancient Persian word. It is said that the word has originated from the dialect of the people living in Pistachio-rich areas of Khorasan province in the south of the Oxus. Pistachio is a tropical fruit. This product was launched in 1737 by someone called "lines" of Spain under the name of "Nakardyasy" (Anacardiacae). The family has 75 genera and 600 species are Pistachio, 9 species are edible and among the most important edible species in Iran, the following can be mentioned: Pistachio vera (Pistachio normal), Pistachio motica (wild Pistachio and Pistachio), Pistachio khinjuck (Pistachio P. khinjuk is now also grown in Sabzevar region). Unlike the almond and walnut trees, Pistachio is a dioecious tree, male and female of which are separated. Pistachio is among the fruits that are fruitful in a year and are less fruitful in the next year [1]. Growth and development of plants depend on the genetic structure of the soil and climate conditions [2]. The stability of agricultural production is one of the most important aspects of sustainable agriculture. The climate and soil are the most important factors of production and land use is based primarily on the quality of these two factors. Climate is the main factor determining the geography of agriculture. The main factor determining patterns of world agricultural is also climate. The agricultural production is highly correlated with precipitation and suitability of the weather conditions in each year. The weather is the only source that people can be free of charge to any amount of use. In our country, because of tight restrictions on rainfall, the unbearable heat in the summer and severe cold in winter, the weather plays an important role in agricultural production [3]. From among the great achievements reached in the field of race, technology, irrigation, pest control and weed and biotechnology, the issue of climate is a key factor in determining agricultural geography. In general, agricultural planning related to planting, harvesting, pest control, irrigation, etc. will have little success without understanding the impact and nature of climate [4].

Knowledge of appropriate times of planting and harvest, and understanding of climatic parameters provide an opportunity for policy makers to think about the allocation of appropriate resources to various products. Study of climate and environmental factors in determining a region's horticultural species today is essential accordingly. Garden management and increased production per area require optimal use of natural resources and recognition of these resources [5].

Agro meteorology is a multi-faceted science that has an important role in crop production, protection of natural resources, and the efforts made in promoting sustainable development in the twenty-first century [6]. The range of the application of meteorology in agriculture begins from the depth of the land, where the plant is rooted, and continues a few meters above the ground level, where crops and fruit trees grow and poultry live. This does not mean that other phenomenon that occurs higher in the atmosphere, meteorology, agriculture is not the issue. Weather conditions such as light intensity, amount of light, temperature, rainfall, wind speed and humidity and the changes are the main factors determining the type of plants in the region having the potential to grow and develop. To be able to crop and garden in a specific area in the area of culture, we have to carefully study the climatic conditions of the region [7].

Agro-meteorology and environmental potentials of each area based on the needs and constraints of weather on different products, identification and thereby producing the best product of its land area are helpful [7]. Weather on all matters relating to agriculture, the planting and harvesting is effective. The effect of weather on agricultural products can be identified in two ways: First, there is a direct relationship between plant growth, particularly herbal products and climate; therefore, agricultural product models were developed related to air swing in a very small area. The first effect of climate on agriculture is in a large area with a larger scale. The second factor to consider is the effect of further research. Weather is important in almost every phase of agricultural activities: the selection of land to crop trials and long-term plans to daily operations [6].

Knowledge of the natural resources and soil, weather conditions expected between the soil surface and the lower atmosphere, and useful guidance for decisions on long-term planning provides agricultural systems [6].

\section{Methods}

\subsection{The Research Question}

How can GIS be used to develop Pistachio cultivation by identifying and analyzing the main characteristics of natural and climatic capabilities of an area? 


\subsection{Hypotheses}

It seems GIS geographic information system, due to climatic factors, Pistachio cultivation in the identification of suitable areas is more effective than traditional methods.

\subsection{Research Purposes}

The objectives of this study was to investigate the status quo climatic parameters such as temperature, relative humidity, rainfall, sunshine, wind, evaporation and transpiration, ER, ice and environmental parameters such as slope, slope direction, topography, soil and water resources and ... and compare them with the needs of climate Pistachio plant. The overall objectives and goals is detailed.

\subsection{The Overall Objective}

- Effects of climate change on the spread of the cultivation of Pistachios in the area.

- Evaluate the Pistachio growing areas due to bioclimatic conditions.

\subsection{Partial Goals}

- Environmental variables and the influence of these factors on the expansion of the cultivation of Pistachios. Such as soil, slope and water suitable for agriculture.

- Preparation of geological layers, soil, rainfall, temperature, relative humidity, land use, vegetation, water requirement, effective rainfall, hydrography, etc. The study area.

\subsection{Background Research}

Pistachio plant that has been cultivated and nurtured in Iran was loaded. Wild and Pistachio forests in the northeastern region bordering Iran and Turkmenistan and Afghanistan, and is believed to be the ancient background Pistachio tree about 4 - 3 thousand years ago, Iran has been domesticated and cultivated business [8].

Pistachio is one of the most important horticultural products mixed with Iran and its production in the country's history. The product of 70 years before starting exports, economic and commercial value has become the country as the first and most important exporter in the world famous [8]. Suffice Pistachio important in this country that has long been called the Green Gold [1].

According to statistics obtained in 73 of the different countries producing Pistachio, only products in seven countries, commercialize, and of 400 thousand tons of Pistachio production in the world of having about $57 \%$ of GDP in the first place, the United States, with 17 percent of the runners and Turkey is in third place with 13\% and U Kerman with 4.81 per cent of the total acreage of trees biggest Pistachio plantation region and the world. Iran still has the first place in 2007, Turkey has a second and a third place is American. World-class research is conducted on Pistachios can be cited articles and books on the subject.

\subsection{Foreign Studies}

In 1956 Caruso and Motisi in an article examined the possibility of the development of Pistachio orchards in East Australia. In this study is to evaluate the Pistachio growing areas in the East of Australia stated that [9]. In an article in the Turkish economy and its Pistachio production and issues the world is examined. In this area, production and prices and foreign trade of Pistachio in Turkey and Iran were compared [10]. two categories Agero Klimia west to the United States that are classified in the first 11 Klimia changing the maximum, minimum and mean temperature of the coldest and warmest months of the year, the average annual temperature, the number of frost days per year, annual precipitation, rain winter and summer rainfall in the classification of the three variables used to altitude, latitude and longitude also added [11]. In the research, production, technology and research projects in Syria's problems were investigated. In this study, a brief description of the Syria Pistachio Industry with the forms and areas of Pistachio production, yield and fruit Pistachio what is expressed [11].

\subsection{Internal Studies}

Indeed, studies in the field of meteorology and climatology in agriculture does not have the integrity and Plan- 
ning. In this equation Meteorological Organization's activities such as research projects in agriculture needs and limitations of Iran's main product, working with Quantum Consulting Engineers, the Institute of Meteorology and Hydrology Romania named [9]. Academic studies on Pistachio in Iran have almost started from about 40 years ago. Ibrahimi evaluated Pistachio cultivation in Kerman. In this study, the climate has been studied for Pistachio cultivation and Kerman has been pointed out as suitable for planting Pistachio. Salari Sharif Abad examined Rafsanjan Pistachio. President Dana (1972) has pointed to the role of the economy in Rafsanjan. In this study, the export and import of Pistachios and its role in the economy has been evaluated highly in the region and the people's livelihood [12].

Kerman Industrial Administration held a seminar entitled examining the issues of packaging and Pistachio economy. Agricultural and economic experts at seminar presented various papers on the packaging, marketing, export, production, and pest control diseases and other aspects of the product. Agriculture Organization of Kerman province held a technical conference on Pistachio in June 1993. In this conference, economic and agricultural experts presented general articles about gardening, agriculture, water and soil, pests, diseases, and Pistachio export [13].

Sheikhi studied the climate and agriculture. In this study the impact of climate on agriculture that are discussed in this paper does not fit all content and for more information please refer to the source [14]. Fattahi Ardakani analyzed the efficiency of factors affecting Pistachio production. Since the economic value of Pistachio is higher than other products of the area under study, Sedaghat (1996) conducted studies to economically evaluate farmers' tendency toward Pistachio and its effect on cropping and income patterns of farmers in Neyriz town. Javanshahy (1999) conducted studies on Pistachio flowering and methods to delay flowering in order to prevent frost damage in spring. However, in addition to the economic value of Pistachio, the economic value of water is proposed that. Tahami Poor (2004) to determine the economic value of water in Pistachio production is Zarand city. Gazrv and Basir (2004) to determine the temperature curves of moisture in the drying temperatures have done the research [14]. Khayat Zade Mahani studied the climatic elements (temperature and humidity) on the cultivation of Pistachios in Rafsanjan city. Keykhosravi studied the feasibility of Pistachio cultivation in Sabzevar city. In this thesis, Sabzevar zoning was examined in terms of Pistachio cultivation in the southern and south-western plains of Sabzevar and the best places to plant Pistachio have been selected [9]. Ghorbani (2005), the role of management skills in the city of Damghan Pistachio yield is paid. In recent years, books have been written on this subject, Vzvayee (2005) and his colleagues evaluated the Handbook of walnut, Pistachio and almonds have translated in this book full of letters describing the genotypes to describe the characteristics of a needs assessment, is described. It is also possible to book Pistachio practical effect Sherafati (2007) that the challenges and solutions in the field of Pistachio and to provide solutions to overcome these challenges noted. Amir Ghasemi (2007) or green gold of Pistachio Iran wrote that the way to planting and harvesting, and the issues are explained later. On the other hand to expand the new agriculture based on scientific basis is needed Everyone has to share in the prosperity and development of sustainable agriculture is diligent and take effective steps in this direction And recognition of the region, the potential and actual shortcomings and inefficiencies and to recognize and resolve defects and inefficiencies in the proper harvest or as managerial and rational endeavor. Because some parts of the study area is located in the desert at the edge of the desert. To prevent the advance of the desert and lower the level of groundwater in the region as well as the climatic conditions and other environmental factors also compatible with the Pistachio in the region, the study of climate and environmental conditions in developing evaluate the Pistachio cultivation is necessary [15].

\subsection{The Introduction of the Study Area}

Catchment area of Roshtkhar plain is located in the south of the catchment area of Torbat Heidarieh plain and on the road from Torbat to Khaf with a longitude of 5.59 to 53.59 and latitude o 52.43 to 18.35. North of the mountain of two horns and the White Mountains, the East mountains and plains Keybr occurring in the south and from the west to the mountains Kahik and broken blood wells underlying is limited. And the height of the highest peak, Mount Garmab altitude of 2560 meters above sea level and the lowest point at 843 meters above sea level is output plain that is. And its height from sea level is 1141 meters [16].

\section{Materials and Methods}

In the study of materials and the tools used to create the database space: 
1) Statistics synoptic stations Meteorological Organization.

2) Topographic maps at the scale of 1:250,000 are provided by the Armed Forces Geographical Organization.

3) The land use map at a scale of 1:250,000 by the Soil and Water Research Institute is provided.

4) Statistics Statistical Yearbook of Agriculture of Khorasan Razavi.

5) Statistics Khorasan Regional Water Authority.

6) Data and data management company based studies of water resources (surface and underground).

7) The use of GIS and related software for data analysis and maps.

8) The use of statistical software such as SPSS and Excel for analysis and statistical calculations.

9) Use the AHP method for weighting the layers.

\section{Findings}

According to Table 1 \& Table 2 in the form of a matrix, weight of each layer is selected and accepted is obtained CI $=0.0732258$ And the weight of each layer is the layer temperature selection with $384,519 / 0$ by weight is capable of maximum value And in order of preference, the next layer to have a lower weight value so that the height of the lowest layer value-weighted (0.0315157) to be allocated And the total level of choice is the number1. If we gather together with their weights obtained is the number 1/00000007. The error of the number 0/00000007 software is too small. How to get the weight of each layer in the software AHP overlap equation

Table 1. Matrix paired comparison evaluation criteria.

\begin{tabular}{|c|c|c|c|c|c|c|c|c|c|}
\hline 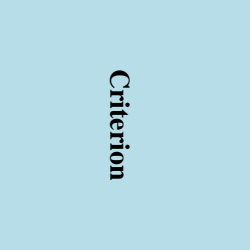 & 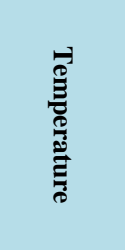 & 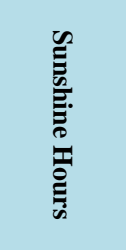 & อి. & $\stackrel{\frac{T}{a}}{\frac{a}{a g}}$ & 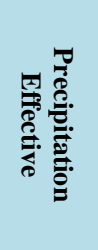 & 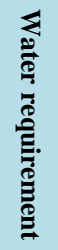 & 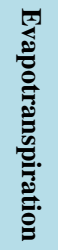 & $\frac{\mathscr{O}}{\frac{\tilde{D}}{\tilde{D}}}$ & 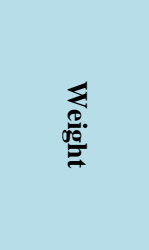 \\
\hline Temperature & 1 & 3 & 4 & 5 & 6 & 7 & 8 & 9 & 0.384519 \\
\hline Sunshine Hours & 0.333 & 1 & 2 & 3 & 4 & 5 & 6 & 7 & 0.2098904 \\
\hline Soil & 0.25 & 0.5 & 1 & 2 & 3 & 4 & 5 & 6 & 0.14606 \\
\hline Height & 0.2 & 0.3333 & 0.5 & 1 & 2 & 3 & 4 & 1 & 0.0857878 \\
\hline $\begin{array}{l}\text { Precipitation } \\
\text { Effective }\end{array}$ & 0.166667 & 25 & 0.3333 & 0.5 & 1 & 2 & 3 & 4 & 0.0687155 \\
\hline Water requirement & 0.142857 & 0.2 & 0.25 & 0.3333 & 0.5 & 1 & 1 & 2 & 0.0391345 \\
\hline Evapotranspiration & 0.125 & 0.166667 & 0.2 & 0.25 & 0.3333 & 1 & 1 & 2 & 0.0344637 \\
\hline Slope & 0.1111 & 0.142857 & 0.16667 & 1 & 0.25 & 0.5 & 0.5 & 1 & 0.03115157 \\
\hline
\end{tabular}

Source: author's calculations.

Table 2. Comparison of binary scale 9 for quantification criteria.

\begin{tabular}{cc}
\hline The importance of & Definition \\
\hline 1 & Define the importance of The importance of \\
2 & Equal importance to average \\
3 & Average of \\
5 & The importance of moderate to strong \\
6 & The importance of strong \\
7 & The importance of strong to very strong \\
8 & The importance of a strong \\
9 & The importance of a strong and powerful \\
\hline
\end{tabular}


formula is calculated as follows:

$$
\mathrm{Si}=\frac{\sum w i \times l i}{\sum \mathrm{w}}
$$

where Si: Equation overlap index,

$\Sigma$ wi: Total weight of each layer,

Li: the weight of its own layer,

$\Sigma \mathrm{w}$ : total weight of the layer, which is the number 1.

For example, the weight of temperature layers is calculated as follows:

$$
\mathrm{Si}=\frac{0.0315157 \times 1}{1}=\frac{0.0315157 \times 1}{1}=0.0315157 \text {. }
$$

After taking the abovementioned steps and obtaining the exact weight of selected layers affecting the development of Pistachio cultivation in the area under study, the obtained weights are entered into GIS, which is shown in Table 3, because of the importance of layers.

According to Table 3, it is observed that 800 to 1100 meters altitude levels are 80.47 percent $\left(73.1725 \mathrm{~km}^{2}\right)$ suitable for Pistachio cultivation. Then, altitudes lower than 800 meters, which is about 67.49 percent (03.1793 sq km) are favorable. Finally, altitude levels of 1100 to 1400 meters, about $61.10 \%$ (36.383 square kilometers), are not so good for cultivation. Altitude levels higher than 1400 meters that form about 40.0\% (68.4 square kilometers) of the study area are located in the highlands.

Direction of slope is one of the most important factors affecting plant growth because the temperature change is very obvious in the three types of slopes, i.e. slopes sun directly radiates on them, slopes relatively benefiting from sunshine, and slopes without any sunshine [18]. It is obvious that slopes that are directed toward sun get more sunshine; therefore, they are suitable for Pistachio cultivation. Therefore, we can use topographical maps and determine the dip angle of the incoming radiation anywhere to calculate it [18]. In this study, slope direction is weighted based on the importance of slope in being exposed toward sun radiations. The weights in order of importance are Southern, Southeast, Southwest, East, West, North, Northeast and Northwest slopes. Table 4 shows aspect as well. For example, when it is said to the southern slope of 157.5 to 202.5, it means the grade to be included.

In Table 5, the direction of slope for planting Pistachio trees is specified with indicators such as very good, average, weak, and inappropriate. Then, based on these indicators, better plans for planting Pistachio were done.

Table 3. Distribution of high levels in the study area.

\begin{tabular}{ccccc}
\hline Area (KM2) & Cover area & Height $(\mathbf{m})$ & Degree of reliability & Class \\
\hline 73.1725 & 80.47 & $800-1100$ & Very Good & A \\
30.1793 & 67.49 & Under 800 & Average & B \\
36.383 & 61.10 & $1100-1400$ & Weak & C \\
68.4 & 40.0 & More than 1400 & Inappropriate & D \\
\hline
\end{tabular}

Source: author's calculations.

Table 4. Ways tilt.

\begin{tabular}{cccccccc}
\hline $\mathbf{E}$ & $\mathbf{W}$ & SE & SW & S & NE & NW & N \\
-5.112 & -5.292 & -5.157 & -5.247 & -5.202 & -5.67 & -5.337 & -5.22 \\
5.67 & 5.247 & 5.112 & 5.202 & 5.157 & 5.22 & 5.292 & $5.337-360$ \\
\hline
\end{tabular}

Table 5. Respects of the dip in the study area.

\begin{tabular}{ccc} 
Degree & Tilt directions & Degree of reliability \\
\hline $5.112-5.247$ & South, Southeast and Southwest & Very good \\
$5.67-5.112$ & Eastern & Average \\
$5.247-5.292$ & Western & Weak \\
$5.292-5.22$ & North, Northeast and Northwest & C \\
\hline
\end{tabular}

Source: author's calculations. 


\section{Conclusion}

Since implementation of sustainable development in the agriculture requires careful planning based on the talents and constraints of resources, selection of products compatible with the climate, requiring less water, and resistant to water shortage, especially in drought conditions, is among the factors optimizing the pattern of water use in agriculture. In order to expand the space for Pistachio cultivation in this study, the meteorological data and environmental data resources were investigated. Due to the large size of the study area (3.598 square kilometers), there is a need for cost and time saving system to analyze data and climate and investigate environmental factors affecting the cultivation of Pistachio and locate areas prone to Pistachio cultivation. In this study, geographic information system (GIS) was used to analyze the data and locate areas prone to Pistachio cultivation. Features and analysis of GIS have an essential role in presenting models, without which environmental planning is impossible because of the large amounts of geographic data on the one hand and the problem of simultaneous analysis of affecting factors on the other hand. After providing the initial data including meteorological data, maps of environmental resources and etc., all were entered into GIS in a digital format. Thematic maps were prepared and extracted after weighting with respect to environmental and climatic characteristics and conditions affecting cultivation of Pistachio in the study area. Due to climatic maps, including maps of elevation, slope, topography, type of land classification map, it can be seen that optimal soil resources in the study area are concentrated in the foothills and plains due to fertile sediment accumulations. However, optimal climatic resources for cultivating Pistachio that is most affected by the temperature are generally at lower altitudes, scattered at south, west, northwest, and center of the study area. There is no possibility for traditional methods because of abovementioned reasons and methods used to find areas prone to Pistachio cultivation in terms of development of Pistachio orchards in the study area. Therefore, the content and accuracy of assumptions underlying the hypotheses are confirmed.

\section{Offers and Solutions}

1) In order to enhance the potential locations carefully cultivated Pistachio and other products, a more accurate base maps prepared by the relevant organizations.

2) It is better to choose the place of Pistachio cultivation of social and economic factors to be considered. For example, in the study area due to the fact that nearly 70 percent of the population, rural (Statistics 2010) suitable employment and productivity, standard of living and a good life for the rural agricultural population.

3) In order to enhance the accuracy of the proposed study area of agricultural research, agricultural research stations required parameters (meteorological, climatic, agricultural, etc.), the exact location and construction of the station by relevant organizations to take the necessary measures done.

4) It is recommended to create a data receiving stations and satellite-to-date information, including the agricultural sector, the agricultural sector is recommended by the directors.

5) It is suggested to create a database based on the latest agricultural information to enable agriculture researchers gain access to required data in a short time. This will lead to prevention of iterative studies, higher accuracy of studies, and exchange of views among researchers.

\section{References}

[1] Abrishami, M.H. (1993) Historical Knowledge of Iranian Pistachios.

[2] Koochaki, A. and Alizadeh, A. (2004) The Principles of Agriculture in Arid Areas. Vol. I, 4th Edition, Astane Ghodse Razavi Publications, Mashhad.

[3] Khayyatzade Mahany, A. (1995) Study of Climatic Factors (Temperature and Humidity) for Pistachio Cultivation in the City of Rafsanjan. MS Thesis, University of Sistan and Baluchestan.

[4] Kavyani, M.R. and Buhlul, A. (1990) Meteorological Bases. SAMT Publications, Tehran.

[5] Rahman Pour, H. (2014) Introduction to GIS and Its Application in Geography. Mashhad.

[6] Ghatrehsamani, M. (2001) The Weather in the Development of Sustainable Agriculture in the Country, the Meteorological Branch.

[7] Parsa, A.A. and Karimian, N. (1975) Effect of Sodium Chloride on Seedling Growth of Two Major Varieties of Iranian Pistachio (Pistacia vera L.). Journal of Horticultural Science, 50, 41-46.

[8] Panahi, B., et al. (1990).A Guide to Pistachio. Department of Horticulture, Pistachio Affairs Office, Gissom Publica- 
tions, Karaj.

[9] Keikhosravi, G. (2009) The Feasibility of Pistachio Orchards in the City of Sabzevar. Master’s Thesis, Martyr Beheshti University.

[10] Jallala, A.M. (2011) Geo-Climate Zones in the Western Region and Their Impact on Agricultural Productivity. M.S.C Thesis, University of Idaho.

[11] Jallala, A.M. (2011) Geo-Climate Zones in the Western Region and Their Impact on Agricultural Productivity. M.S.C Thesis, University of Idaho.

[12] Ebrahimi, A. (2010) Kerman Pistachio. Thesis, National University.

[13] Amir Ghasemi, T. and Soozani, J. (2007) Pistachio or Green Gold in Iran. Publications of Council of Agriculture and Natural Resources, Tehran.

[14] Sheikhi, H., et al. (2007) Evaluation of Kriging Interpolation and Regression Analysis Based on DEM in the Preparation of Annual Isorain Map in Khorasan Razavi Province. Geographical Research Quarterly, No. 83, Ss 1-12.

[15] Azimi Hosseini, M., et al. (2009) Use of GIS in Locating. Mehregan Ghalam Publications, Tehran.

[16] Janghi, H. (2013) Roshtkhar on the Path to Sustainable Development. Publishing Aria, Mashhad.

[17] Azimi Hosseini, M., et al. (2009) Use of GIS in Locating. Mehregan Ghalam Publications, Tehran.

[18] Amirbeygy, R. (2014) Herb. Geographic Information Systems, Management, Geographic Information Systems Mapping Agency, the National Cartographic Center.

\section{Submit or recommend next manuscript to SCIRP and we will provide best service for you:}

Accepting pre-submission inquiries through Email, Facebook, LinkedIn, Twitter, etc. A wide selection of journals (inclusive of 9 subjects, more than 200 journals)

Providing 24-hour high-quality service

User-friendly online submission system

Fair and swift peer-review system

Efficient typesetting and proofreading procedure

Display of the result of downloads and visits, as well as the number of cited articles

Maximum dissemination of your research work

Submit your manuscript at: http://papersubmission.scirp.org/ 